\title{
Hydatid Cyst of the Lung in Children: A Diagnosis Not to Be Missed
}

\author{
Ahmed Khalil BEN ABDALLAH ${ }^{1,2}$, *Mohamed ZOUARI ${ }^{1,2}$, Manel HAJ MANSOUR ${ }^{1,2}$, \\ Imen ABID ${ }^{1,2}$, Mahdi BEN DHAOU ${ }^{1,2}$, Mohamed JALLOULI I,2, Riadh MHIRI 1,2
}

1. Department of Pediatric Surgery, Hedi-Chaker Hospital 3029 Sfax, Tunisia

2. Sfax Medical School, Sfax, Tunisia

*Corresponding Author: Email: zouarimohamed.1982@yahoo.fr

(Received 16 Apr 2018; accepted 24 Apr 2018)

\section{Dear Editor-in-Chief}

Hydatid disease is an important public health problem in many Mediterranean and Middle East countries (1). "This disease is endemic in Tunisia. The annual incidence of chirurgical hydatid disease is 15/100000 in the Tunisian population" (2). The lungs are the most common sites of infection in children (3). The initial infection, as well as the development of a cyst, remains asymptomatic for many years. In some patients, symptoms such as dyspnea, coughing, and nausea and vomiting related to pressure may occur (4). The diagnosis is may be made incidentally on chest radiographs or CT scans (4). Surgery is the preferred treatment. Sole medical treatment is reserved for disseminated disease and inoperable patients (5).

The aim of the present study was to identify the epidemiological, diagnostic, and therapeutic features of pulmonary hydatidosis in children. Thirty patients under the age of $14 \mathrm{yr}$, operated between Jan 2009 and Dec 2016 due to pulmonary hydatid cysts, were evaluated retrospectively. All patients had chest radiographies and abdominal ultrasonography scans. Computed tomography scan was performed in $11(36.6 \%)$ patients.

Written informed consent was obtained from the legal guardian of each patient to publish the case and accompanying images in scientific journals for research and educational purposes.
There were 21 boys and 9 girls. The mean age of our patients was $8.12 \pm 2.5$ yr. Twenty-eight $(93.3 \%)$ patients were of rural origin. The symptoms at the time of presentation were coughing in $30 \%(\mathrm{n}=9)$, hemoptysis in $20 \%(\mathrm{n}=6)$, and chest pain in $40 \%(n=12)$. The diagnosis was made incidentally on chest radiography in $10 \%$ $(\mathrm{n}=3)$. The average cyst diameter was $6.36 \pm 1.8$ $(3-10) \mathrm{cm}$. The cysts involved the left lung in 16 $(63.6 \%)$ patients, the right in $11(36.4 \%)$. Three $(10 \%)$ patients had bilateral lung cysts (Fig. 1).

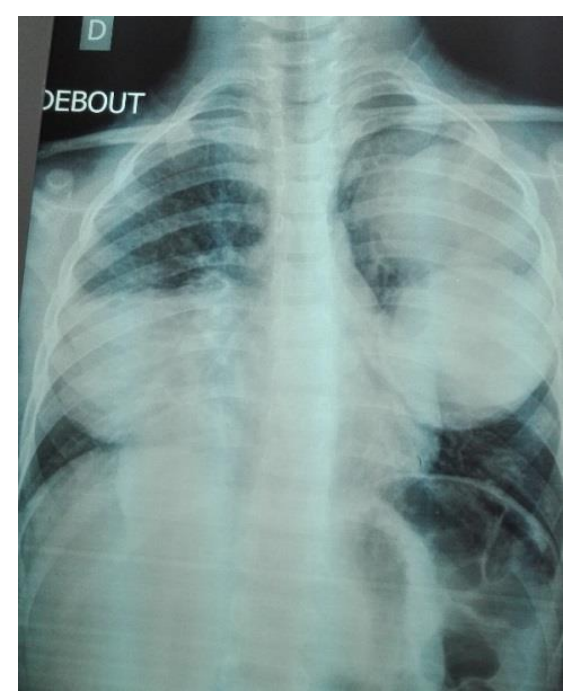

Fig. 1: Radiography shows multiple hydatid cysts of the lungs, one in the right side and two in the left side 
The most common location of cysts was in the left lower lobe $(40 \%, \mathrm{n}=12)$. Serological tests were positive in $22(73.3 \%)$ patients. Twelve (40\%) patients had perforated cysts. A liver hydatid cyst was found in $3(10 \%)$ patients. One patient had multiple cysts with involvement of the lungs, the liver and the left kidney (Fig. 2). All of the patients were managed surgically. Posterolateral thoracotomy and cyst excision were performed in all patients. Three liver cysts were $>5$ $\mathrm{cm}$ and were managed with the puncture, aspiration, injection, and reaspiration (PAIR) tech- nique. The lung was treated first in patients with concomitant lung and liver involvement. A second operation was performed for the liver within 2 to 4 months after the lung operation. In all patients, Albendazole was given perioperatively at a dosage of $10 \mathrm{mg} / \mathrm{kg}$ per day and was continued postoperatively for 2 months. The average follow-up period was $32.5 \pm 23.3$ months. No allergic reactions were observed, and there were no recurrences, owing to the preoperative planning and meticulous perioperative precautions to prevent spillage.

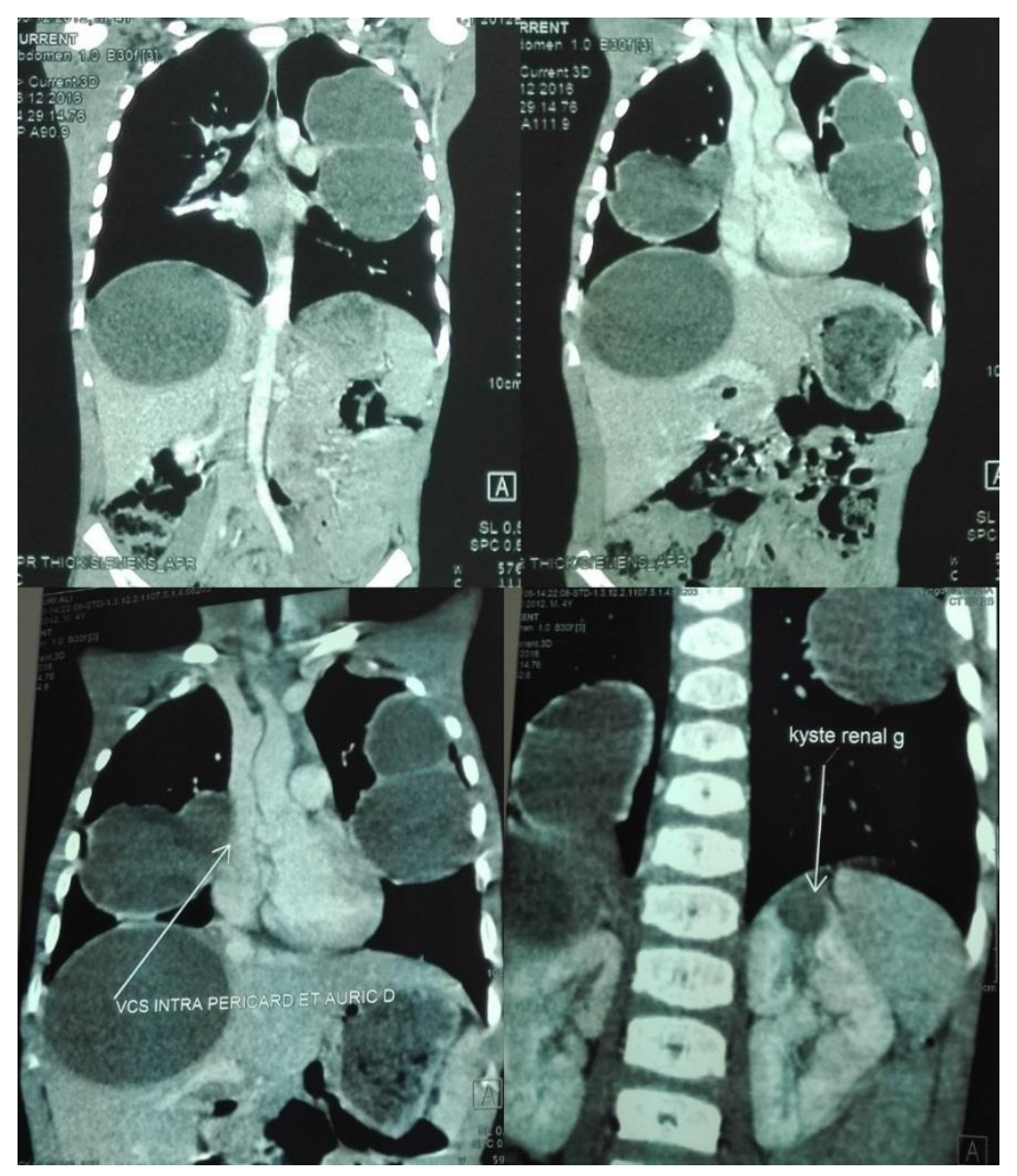

Fig. 2: Chest and abdominal computed tomography images showing multiple cysts with involvement of the lungs, the liver and the left kidney

Although hydatid disease has been controlled in many countries, this zoonosis remains endemic in some regions, especially in developing countries. A high index of suspicion is needed to make the diagnosis. During surgical removal of hydatid cysts, we must avoid spillage of cyst contents to prevent anaphylactic reaction, recurrence and multiple hydatidosis. Prophylactic Communitybased measures are crucial to treatment strategy. These measures include people education, treat- 
ment and control of all dogs, and proper hand washing after contact with dogs or their feces.

\section{Source of Support: Nil.}

\section{Conflict of interest}

The authors declare that there is no conflict of interests.

\section{References}

1. Santivanez S, Garcia HH (2010). Pulmonary cystic echinococcosis. Curr Opin Pulm Med, 16(3):257-61.
2. Oudni-M'rad M, M'rad S, Gorcii M, et al (2007). [Cystic echinococcosis in children in Tunisia: fertility and case distribution of hydatid cysts]. Bull Soc Pathol Exot, 100(1):10-3.

3. Topcu S, Kurul IC, Tastepe I, et al (2000). Surgical treatment of pulmonary hydatid cysts in children. J Thorac Cardiovasc Sung, 120(6):1097101.

4. Witzke HJ, Anikin V (2017). Other conditions of the lung (abscesses, inhaled foreign bodies, bullous lung disease, hydatid). Surgery (Oxford), 35(5):269-73.

5. Gottstein B, Reichen J (2002). Hydatid lung disease (echicoccosis/ hydatidosis). Clin Chest Med, 23(2):397-408. 